\title{
IL-6 Plays a Crucial Role in HBV Infection
}

\author{
Tian Lan, Lei Chang, Long Wu and Yu-Feng Yuan* \\ Zhongnan Hospital of Wuhan University, Department of Hepatobiliary Surgery, Wuhan University, Wuhan, China
}

\begin{abstract}
Interleukin-6 (IL-6), a cytokine mainly produced by activated monocytes, has broad pleiotropic actions that affect the functions of a variety of lymphoid cells. The roles of IL-6 in regulating immunity to infections are currently being defined. Remarkably, IL-6-mediated cellular and humoral immune responses play a crucial role in determining the outcome of viral infection. This article reviews the current knowledge on the critical role of IL- 6 in hepatitis B virus (HBV) infection. As a competent intermediary, IL- 6 derived from activated monocytes plays an important role in promoting lymphocytes responses that are essential for effective viral control. However, as a mediator of inflammation, IL- 6 is also involved in the development of $\mathrm{HBV}$-induced liver cirrhosis and exacerbating liver injury. Overall, the current data point to IL-6 as an immunoregulatory cytokine in HBV infection. Immunotherapeutic strategies aimed at optimizing the beneficial effects of IL- 6 in HBV infection may prove to be an ordeal in the future, as they should foster the strengths of IL-6 while circumventing potential drawbacks.

(C) 2015 The Second Affiliated Hospital of Chongqing Medical University. Published by XIA \& HE Publishing Ltd. All rights reserved.
\end{abstract}

\section{Introduction}

Hepatitis $B$ virus (HBV) is the most common virus with the potential to cause human liver disease, including self-limiting acute hepatitis, chronic hepatitis, fulminant hepatic failure, liver cirrhosis and hepatocellular carcinoma (HCC). The latter three diseases often result in death. Worldwide, HBV causes

Keywords: Interleukin-6; HBV infection; Immunoregulation.

Abbreviations: $A E$, acute exacerbation; $A P 1$, activating protein-1; $C A H$, chronic active hepatitis; cccDNA, covalently closed circular DNA; CSH, chronic severe hepatitis; CTL, cytotoxic T lymphocytes; Enh1, enhancer 1; ERK, extracellular signal regulated kinase; $\mathrm{HBeAg}$, hepatitis $\mathrm{B}$ early antigen; $\mathrm{HBsAg}$, hepatitis $\mathrm{B}$ surface antigen; HBV, hepatitis B virus; HCC, hepatocellular carcinoma; HNF, hepatocyte nuclear factor; HTLV-1, human T-Iymphotropic virus type 1; IGF, insulinlike growth factor; IGFIR, IGF 1 receptor; IL-1, interleukin-1; IL-6, interleukin-6; IRAK, IL-1 receptor associated protein kinase; NF-кB, nuclear factor kappa B; NK, natural killer; $\mathrm{NTCP}, \mathrm{Na}(+)$ /taurocholate cotransporting polypeptide; PWM, poke weed mitogen; RT, radiotherapy; SIg, secretory immunoglobulin; SNP, single nucleotide polymorphism; SPA, staphylococcal protein A; STAT3, Signal Transducer and Activator of Transcription-3; TNF, tumor necrosis factor.

Received: 27 July 2015; Revised: 17 September 2015; Accepted: 11 October 2015 DOI: $10.14218 /$ JCTH.2015.00024.

*Correspondence to: Yu-Feng Yuan, Zhongnan Hospital of Wuhan University, Department of Hepatobiliary Surgery, Wuhan University, Wuhan 430071, Hubei, China. Tel: +86-027-67812888, Fax: +86-027-67812892, E-mail: yuanyf1971@163.com an estimated 250,000 deaths per year and is a significant public health problem. Hepatitis $B$ is an immune-related disease, and the hepatocellular injury caused by HBV is indirect and is induced by an immune response that results in hepatocellular degeneration and necrosis and hyperplasia of hepatic fibrous tissue. A complete and specific immune response against HBV can completely eradicate the virus in infected hepatocytes. ${ }^{1}$ However, mounting an inappropriate immune system response results in one of the primary clinical presentations of HBV-related diseases. ${ }^{2}$ The mechanisms underlying these persistent and progressive HBV infections remain unknown. A number of factors, such as virus subtype, host condition, and environmental and genetic factors, affect the outcome of HBV infections. In addition, host immunological and genetic factors play important roles in the pathogenesis of hepatitis $\mathrm{B}^{3}$ The current consensus is that cytokines and regulatory molecules are involved in generating an appropriate immune response to eradicate an HBV infection. Interleukin (IL)- 6 is a multifunctional, potent, pleiotropic inflammatory cytokine and is a key immune response regulator. ${ }^{4}$ IL-6 inhibits macrophages to produce IL-1 and tumor necrosis factor (TNF), which has been shown to mediate protective and anti-inflammatory effects in endotoxin-induced lung injury. According to many studies, IL-6 expression is increased differentially in response to inflammation, infection, and the presence of certain tumors. ${ }^{5-7}$ Thus, IL-6 is a sensitive index for disease severity and prognosis. It seems that IL-6 can play crucial roles in the induction of immune-tolerance against HBV antigens, and its activity is likely to be involved in the determination of outcomes of hepatitis $B$ patients. Here we review the most recent information concerning the relationship between IL- 6 and HBV infection.

\section{Introducing IL-6}

Human IL-6 is a glycosylated protein with a molecular weight of $26 \mathrm{kD}$. The gene is located on chromosome 7 and contains 5 exons and 4 introns. The IL- 6 precursor peptide is composed of 212 amino acids (aa). The IL- 6 gene promoter region contains important transcriptional control elements that are regulated by nuclear factor kappa $\mathrm{B}(\mathrm{NF}-\kappa \mathrm{B})$ and activating protein-1 (AP1), among other proteins.

The IL- 6 receptor is composed of the IL- 6 binding receptor protein (IL-6R) and a universally expressed $130 \mathrm{kD}$ signaltransducing $\beta$-receptor (gp130). ${ }^{8}$ An important marker of IL-6 activity, gp130 is a glycopeptide expressed on the surface of most cells and is capable of trans-membrane signaling. In contrast, IL-6R expression is restricted largely to hepatocytes, leukocytes and megakaryocytes, ${ }^{9}$ and the soluble form of IL-6R (SIL-6R) has been found in a variety of bodily fluids. ${ }^{10} \mathrm{~A}$ study by Matthews identified two modes 
of SIL-6R production: direct release into extracellular fluids upon synthesis and catabolic release from the membrane following limited proteolysis. ${ }^{11}$

IL- 6 transmembrane signal transduction can be divided into two types: classical signaling pathways and a transsignaling pathway. In the classical signaling pathways, binding of IL-6 to IL-6R activates the receptor-associated gp130 to transmit secondary signals in cells. ${ }^{12}$ However, in the trans-signaling pathway, IL- 6 first combines with the subunit IL-6Ra, which exists unbound in the extracellular fluid, to form the IL-6/IL-6Ra complex. This complex can then be coupled to the gp130 subunit on the surface of the plasma membrane to complete signal transduction. ${ }^{13}$

IL-6 was originally prepared and purified by Hirano et al. from the culture supernatant of mitogen- or antigenstimulated human T-lymphotropic virus type 1 (HTLV-1)transfected T lymphocytes. ${ }^{14}$ These authors elucidated the $\mathrm{N}$-terminal amino acid sequence and successfully cloned the cDNA encoding human IL-6.

Activated monocytes are the main source of IL-6 in blood. When inflammation occurs, monocytes and macrophages are the first reactive cells that produce IL- $6 .{ }^{15}$ Thus, IL-6 was initially thought to promote $T$ lymphocyte population expansion and activation, promote $B$ lymphocyte differentiation, and regulate the acute-phase response. ${ }^{16}$ Fibroblasts and some tumors, such as cardiac myxoma, cervical carcinoma, and myeloma, spontaneously produce IL-6. ${ }^{17-19}$ In vitro, dendritic cells secrete IL-6. Therefore, almost all stromal and immune cells are capable of producing IL-6. IL-1b and TNF are major activators of IL- 6 expression. Other pathways, such as toll-like receptors, prostaglandins, adipokines, and cytokines, can also regulate IL- 6 synthesis. We now know that IL- 6 has hormone-like functions that contribute to cardiovascular disease, lipid metabolism, insulin resistance, mitochondrial activity, and neuroendocrine regulation. ${ }^{20,21}$ However, the most important biological activity of IL- 6 is immunoregulation, as IL- 6 deficiency can lead to dysfunctional innate and adaptive immunity against many infections. ${ }^{22,23}$ Puel et al. reported a case in which a child with autoimmunity against IL-6 developed recurring staphylococcal cellulitis and subcutaneous abscesses. ${ }^{24}$ Similarly, patients with Job's syndrome, who harbor mutations in the gene encoding signal transducer and activator of transcription-3 (STAT3), exhibited impaired IL- 6 activity and were susceptible to almost all types of recurrent infections. According to the literature, IL- 6 exhibits both pro- and antiinflammatory functions in innate immunity. ${ }^{25}$ Due to its bidirectional capabilities, the effect of IL- 6 is dependent on its expression level in a given tissue. Normal levels of IL-6 expression are conducive to immunological homeostasis, whereas excessive production can cause a series of inflammatory lesions, leading to such diseases as rheumatoid arthritis, Crohn's disease, and glomerulonephritis. ${ }^{26-28}$ Transgenic mice overexpressing IL- 6 developed a variety of disorders, including pulmonary fibrosis, hypertension, multiple myeloma, plasmacytosis, and neurological disease. ${ }^{29-31}$

As a lymphocyte-stimulating factor, IL- 6 can induce B cells to differentiate into antibody-secreting cells and induce the latter to transcribe mRNA encoding secretory immunoglobulin (SIg), thereby increasing the secretion of IgM, IgG, and IgA antibodies. ${ }^{32}$ Muraguchi et al. demonstrated that B lymphocytes activated by staphylococcal protein A (SPA) or poke weed mitogen (PWM) could synthesize immunoglobulin. ${ }^{33}$ The addition of anti-IL- 6 monoclonal antibody prevented this effect, suggesting that IL- 6 is required for the production of antibodies by B lymphocytes. Previous studies have demonstrated the role of IL- 6 as a central link between T cell and $B$ cell responses. ${ }^{34,35}$ Human IL-6 is a terminal cofactor of cytotoxic $T$ lymphocytes (CTL), and the ability of IL- 6 to promote adaptive immunity has been linked to helper $T$ cells and regulatory $T$ cells through the interaction with other cytokines. ${ }^{36}$

\section{IL-6 and HBV infection}

Given the role of IL- 6 in balancing the differentiation of proand anti-inflammatory cells, it follows that it may play an important role in the progression of HBV infections. A number of studies have shown that IL- 6 serum levels are increased in HBV-infected patients and are significantly higher in patients with severe, acute infections than patients with a chronic active infection. Chronically affected patients exhibited significantly higher IL-6 levels during the acute jaundice stage. ${ }^{37-39}$ HBV can infect peripheral blood monocytes, and can actively replicate in these cells. ${ }^{40}$ In chronic active hepatitis $(\mathrm{CAH})$, the decrease in the processing of antigens by Kupffer cells and the polyclonal activation of intestinal antigens increased serum IL- 6 levels. ${ }^{41}$ In chronic severe hepatitis (CSH), massive necrosis of hepatocytes, loss of Kupffer cell phagocytosis, and endotoxemia, which is attributed to adecrease in intestinal mucosa function and default in endotoxin elimination due to liver injury, stimulated the mononuclear phagocyte system to produce more IL-6. In addition, since the liver is the major organ responsible for the elimination of IL- 6 , severe injury of the liver will impair removal of IL-6, leading to an increase in plasma levels of IL-6. Simultaneously, high levels of IL- 6 can induce proliferation and differentiation of cytotoxic T-cells, ${ }^{42}$ causing liver inflammation and the destruction of immunological cells. In patients with chronic hepatitis B, IL- 6 levels in hepatitis $B$ early antigen $(\mathrm{HBeAg})(+)$ and HBV-DNA $(+)$ patients were significantly higher than $\mathrm{HBeAg}(-)$ and HBV-DNA (-) patients. After treatment with interferon, IL-6 serum levels decreased significantly in HBeAg $(+)$ and HBV-DNA (+) patients, indicating that HBV replication is related to IL-6 levels and that high IL- 6 levels have a synergistic antiviral effect. ${ }^{43}$ Therefore, IL- 6 may be a useful marker for monitoring disease activity and therapeutic efficacy in patients with hepatitis B. Undetectable serum IL-6 levels $(<3 \mathrm{pg} / \mathrm{mL})$ during the early stage of acute exacerbation (AE) in patients with chronic hepatitis B can signify patients who will have favorable clinical outcomes, indicating that IL- 6 may be a useful clinical predictor of prognosis. ${ }^{44}$ Furthermore, Zhang et al. detected the serum concentrations of IL-6 in 18 patients with chronic virus hepatitis $B(\mathrm{CH}), 14$ patients with hepatitis cirrhosis ( $\mathrm{HC}$ ) without ascites, and $22 \mathrm{HC}$ patients with ascites $(\mathrm{HC})$. In the 18 patients with $\mathrm{CH}$, serum IL-6 concentrations were the lowest. IL- 6 level in the $22 \mathrm{HC}$ patients with ascites was significantly higher than that in the 14 HC patients without ascites, indicating that IL- 6 may participate in the pathological process of $\mathrm{CH}$ and that cirrhosis could play an important role in ascites formation. ${ }^{45}$

Nevertheless, the mechanisms of adhesion and invasion of human hepatocytes by HBV virus particles remain unclear. De Meyer et al. hypothesized that IL-6 participates in the interaction between the HBV viral particle and the hepatocyte plasma membrane. HBV can bind the preS1 domain, which is likely an important attachment site on human hepatocytes 
Lan T. et al: Interleukin-6 and hepatitis B virus

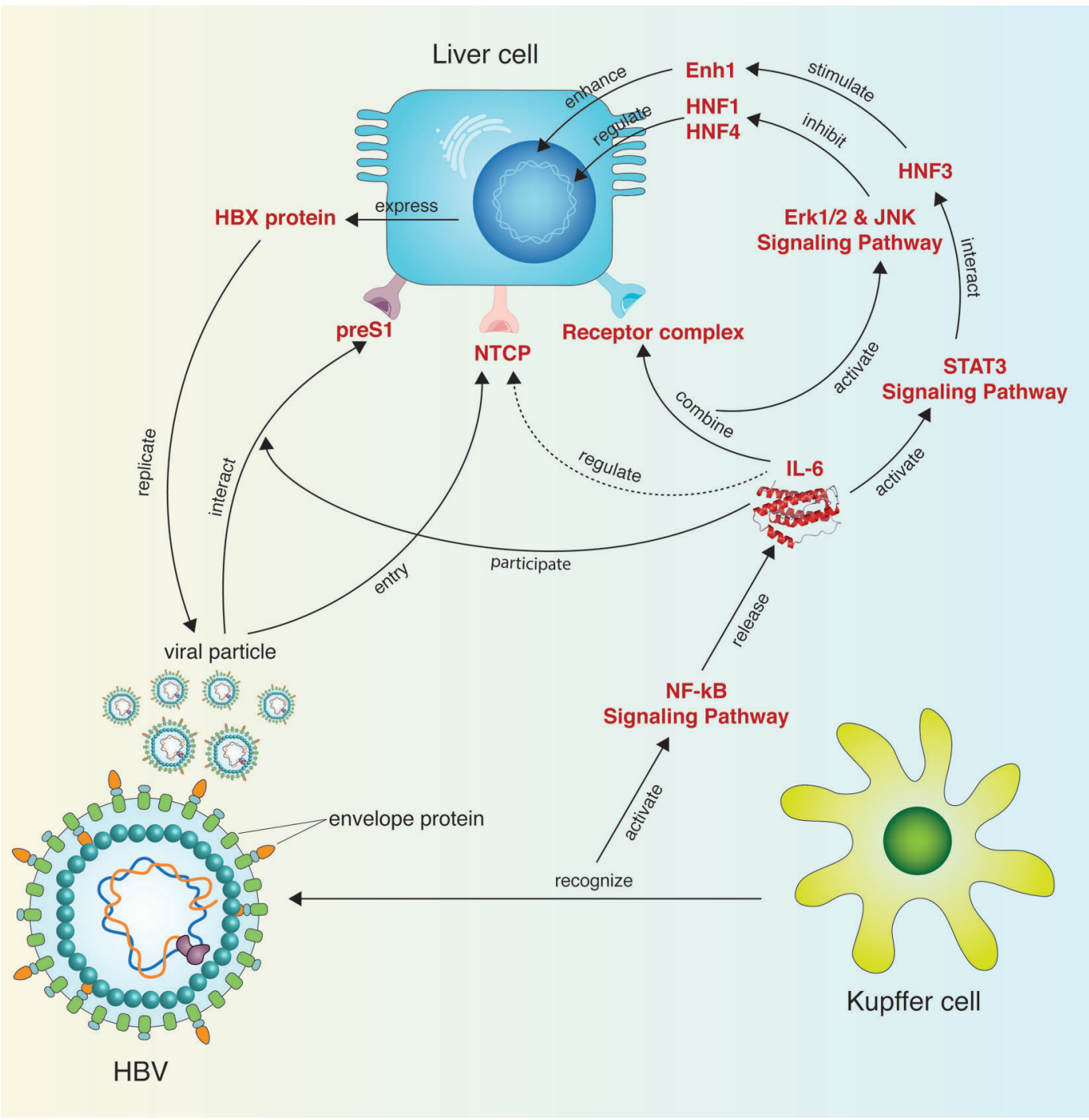

Fig. 1. Potential mechanism of IL-6 on the HBV infection.

that mediates HBV infection (Fig. 1). ${ }^{46}$ Another study indicated that the HBV envelope protein is critical during the infection process and is recognized by nonparenchymal liver cells (predominantly liver macrophages (Kupffer cells), although they are not infected). ${ }^{47}$

By activating certain signaling pathways, IL- 6 can increase the activity of the HBV enhancer 1 (Enh1) to control the expression of HBV $X$ protein (HBX) and the replication of HBV (Fig. 1). ${ }^{48}$ A study by Chou et al. identified IL- 6 as the main bystander mediator of radiotherapy (RT)-induced HBV replication. HBV transgenic mice were treated with whole liver RT and IL-6. HBV core protein staining confirmed the augmentation of intrahepatic HBV replication. Simultaneously, in HepG2 hepatoma cells that received the same treatment in vitro, a similar conclusion was reached. Furthermore, RT of the liver and longer, sustained IL-6 levels induced HBV reactivation through the interaction of phosphorylated STAT3/hepatocyte nuclear factor (HNF)-3 complex with HBV Enh1 (Fig. 1). ${ }^{49}$ In turn, $\mathrm{HBx}$ expression in human hepatocytes and hepatoma cells has been shown to activate the IL- 6 gene and stimulate IL- 6 protein synthesis, a process that requires the participation of IL-1 receptor associated protein kinase (IRAK)-1, p38/ extracellular signal regulated kinase (ERK), or NF-кB (Fig. 1). ${ }^{50-52}$ These results indicated that the sensitivity of hepatocytes and hepatoma cells to $\mathrm{HBx}$ is considerably different. Hepatocytes synthesize and secrete much more IL-6 than hepatoma cells, and they react differently than hepatoma cells to IL- 6 stimulation during the regulation of HBV replication. It has been reported that IL- 6 in hepatoma cells may stimulate HBV transcription by activating STAT-3, which interacts with HNF3 bound to the HBV enhancer (Fig. 1). ${ }^{49}$ In contrast, Kuo et al. demonstrated that IL- 6 effectively suppressed HBV replication and prevented the accumulation of HBV covalently closed circular DNA (cccDNA) in HepG2 hepatoma cells. ${ }^{53}$ Furthermore, Hosel et al. found that recognition between the HBV envelope proteins and Kupffer cells led to activation of NF- $\mathrm{BB}$ and the release of IL-6, which activated mitogen-activated protein kinases, including ERK $1 / 2$ and 
c-jun $\mathrm{N}$-terminal kinase. These kinases inhibited the expression of the transcription factor HNF1 and HNF4, which are essential for HBV gene expression and replication (Fig. 1). ${ }^{47}$ The authors posit that IL- 6 ensures early virus control, limits the activation of the adaptive immune response, and prevents the death of HBV-infected hepatocytes. Similarly, the effect of IL-6 on hepatocytes is also controversial. IL- 6 levels increase significantly during severe hepatitis, and IL- 6 is involved in the activation of natural killer (NK) cells and CTLs that induce the killing of hepatocytes, indicating that IL-6 plays an important role in liver cell necrosis and apoptosis. ${ }^{42}$ However, according to Klein et al., IL-6 is beneficial during liver injury. ${ }^{54}$ The expression of IL-6-gp130-STAT3dependent genes can protect hepatocytes from injury via regulatory $T$ cells, which promote the regeneration of liver cells and reduce the effect of various damaging factors, such as alcohol and carbon tetrachloride. ${ }^{54}$

Clinically, although serum IL-6 levels are positively related to disease severity and HBV-DNA load, therapeutic neutralization of IL- 6 as a treatment for certain diseases may be risky if the patient is infected with HBV. ${ }^{47}$

The HBx protein plays a critical role in the development of HBV-related $\mathrm{HCC}^{55}$ Previous studies have shown that numerous $\mathrm{HBx}$-altered genes and signaling pathways contribute to tumorigenesis via hepatocytes..$^{56-58} \mathrm{Li}$ et al. observed that the $\mathrm{HBX}-\mathrm{miR}-21$ pathway was up-regulated in $\mathrm{HCC}$ cells and that $\mathrm{HBx}$ expression in Hep3B and PLC/ PRF/5 cells significantly suppressed miR-21 expression, which is mediated by the HBx-induced IL- 6 pathway with subsequent activation of the STAT3 transcription factor. ${ }^{59}$ Another study demonstrated that high IL- 6 serum levels were significantly correlated with high OCT4/NANOG expression in HBV-related HCC, and early tumor recurrence was regulated by IL6-induced insulin-like growth factor (IGF)/ IGF 1 receptor (IGFIR) activation. ${ }^{60}$

Recently, the human liver bile acid transporter $\mathrm{Na}(+) /$ taurocholate cotransporting polypeptide (NTCP) was identified as an HBV specific receptor, and silencing NTCP was shown to inhibit HBV and HDV infection (Fig. 1). ${ }^{61}$ Another study demonstrated that IL- 6 inhibited HBV entry by regulating NTCP expression in a dose- and time-dependent manner. ${ }^{62}$

IL-6 is important for the progression of chronic forms of hepatitis B infection and plays a critical role in HBV-induced fibrosis, liver cirrhosis, and HCC. Thus, IL- 6 can be regarded as a risk factor for hepatitis B and its associated complications. Additional research is required to elucidate the mechanisms of IL- 6 in the process of HBV infection.

\section{IL-6 gene polymorphism and HBV infection}

IL-6 is a highly polymorphic gene, and several regions have been identified that may be responsible for its variable protein expression, including three variations upstream of its coding sequence at positions $-174,-572$, and $-597 .{ }^{63}$ Furthermore, genotype and allele frequency vary widely among different races. Among Caucasian and Indian populations, the gene frequency of the $C$ allele $(-174 \mathrm{G}>\mathrm{C})$ ranges from $0.4-0.55$, whereas among the African American population, the gene frequency of this allele ranges from $0.5-0.9 .^{64}$ Early work posited that IL-6 gene polymorphism was not significantly correlated with susceptibility to HBV infection or the progression of HBV-related diseases. ${ }^{63}$ However, these studies were small in scale, and the data were not convincing. A subsequent investigation demonstrated that the $-174 \mathrm{G} / \mathrm{C}$ single nucleotide polymorphism (SNP) in the IL-6 promoter region increased the transcription and expression of IL-6, and serum IL-6 level was found to be associated with the progression of HBV-related HCC. ${ }^{65}$ A study by Lu et al. indicated that the IL-6 -572 G allele may be beneficial for spontaneous HBV clearance, but the allele and genotype frequencies of $-597 \mathrm{G} / \mathrm{A}$ were not significantly different between patients with chronic HBV infections and patients who spontaneously recovered. ${ }^{66}$ Similarly, Dai et al. observed the genotypes $-174 \mathrm{G} / \mathrm{C},-572 \mathrm{G} / \mathrm{C}$ and $-597 \mathrm{G} / \mathrm{A}$ in 160 Chinese patients infected with HBV and 212 healthy blood donors. ${ }^{67}$ The authors found that there was no link between HBV resistanceand the $-174 \mathrm{G} / \mathrm{C}$ and $-597 \mathrm{G} / \mathrm{A}$ alleles, but a significant difference at the $-572 \mathrm{G} / \mathrm{C}$ loci was observed between the HBV infected patients and healthy controls. A hospitalbased, case control study of SNPS in the IL- 6 promoter region involving 381 cases of HBV-related HCC, 340 hepatitis B surface antigen (HBsAg) carriers, and 359 nontumor controls ${ }^{68}$ revealed significant differences among the three groups in the $-572 \mathrm{G} / \mathrm{C}$ allele of the IL- 6 gene. Compared to the CC genotype, the GG genotype was correlated with an increased risk of HBV infection but was not associated with HCC. A recent study found that among Indian people, the IL-6 (-572G>C) GC genotype was positively associated with hepatitis among controls and was negatively associated with cirrhosis and consequent HCC development among carriers. Furthermore, the IL-6 (-597G>A) GA genotype was potentially protective against hepatitis, cirrhosis, and subsequent HCC development in carriers. ${ }^{69}$ In conclusion, these data illustrate how SNPs in the IL- 6 gene promoter fundamentally determine low and high risk among HBVinfected patients.

\section{Conclusions}

IL- 6 is a key mediator of inflammation and the acute phase response of the liver. IL- 6 has been shown to prevent apoptosis during HBV infections, and serum levels of IL-6 are increased in HBV-infected patients. In addition, serum IL- 6 levels are positively correlated with disease severity. Thus, IL- 6 may be a useful indicator of disease activity and therapeutic efficacy in patients with hepatitis B. It is currently thought that IL- 6 increases the activity of Enh1 to control HBx expression and HBV replication through activation of the IL-6R/gp130/STAT-3 signaling pathway. In contrast, HBx (in combination with IRAK-1, p38/ERKs, or NF-кB) can activate the IL- 6 gene and stimulate IL- 6 protein synthesis. However, the protective effect of IL- 6 on hepatocytes during liver injury is controversial. Numerous studies have suggested that the SNP -572 G/C in the IL-6 gene promoter region is significantly correlated with susceptibility to $\mathrm{HBV}$ infection and progression of HBV-related diseases.

Recently, IL- 6 has become a target of therapeutic interventions aimed at reducing the progression of inflammatory autoimmune diseases and cancers. One popular strategy is a combination therapy consisting of IL- 6 blockade and conventional drugs; this approach has resulted in improved treatment efficacy and patient response compared with monotherapy. ${ }^{70,71}$ As IL-6 is closely linked to the development of HBV infection, which is accompanied by immune disorders and tumorigenesis, we speculate that IL- 6 blockade could boost treatment efficacy in patients with HBV-related diseases. Therefore, similar clinical trials are urgently needed to elucidate the pathogenesis of IL- 6 function and 
confirm the role of IL-6 in the progression of HBV-related diseases.

\section{Conflict of interest}

None.

\section{Author contributions}

Drafting the manuscript (TL), revising the manuscript (LC), designing the figure (LW), conceiving this work, giving critical comments and editing the manuscript (YFY).

\section{References}

[1] Ahmadabadi BN, Hassanshahi G, Arababadi MK, Leanza C, Kennedy D. The IL-10 promoter polymorphism at position -592 is correlated with susceptibility to occult HBV infection. Inflammation 2012;35:818-821. doi: $10.1007 /$ s10753-011-9381-x.

[2] Chisari FV, Isogawa M, Wieland SF. Pathogenesis of hepatitis $B$ virus infection. Pathol Biol (Paris) 2010;58:258-266. doi: 10.1016/j.patbio.2009.11.001.

[3] Thursz M. Genetic susceptibility in chronic viral hepatitis. Antiviral Res 2001; 52:113-116. doi: 10.1016/S0166-3542(01)00175-9.

[4] Ishihara K, Hirano T. IL-6 in autoimmune disease and chronic inflammatory proliferative disease. Cytokine Growth Factor Rev 2002;13:357-368. doi: 10.1016/S1359-6101(02)00027-8.

[5] Giannitrapani L, Cervello M, Soresi M, Notarbartolo M, La Rosa M, Virruso L, et al. Circulating IL- 6 and sIL-6R in patients with hepatocellular carcinoma. Ann N Y Acad Sci 2002;963:46-52. doi: 10.1111/j.1749-6632.2002.tb04093.x.

[6] Song le H, Binh VQ, Duy DN, Kun JF, Bock TC, Kremsner PG, et al. Serum cytokine profiles associated with clinical presentation in Vietnamese infected with hepatitis B virus. J Clin Virol 2003;28:93-103. doi: 10.1016/S13866532(02)00271-8.

[7] Porta C, De Amici M, Quaglini S, Paglino C, Tagliani F, Boncimino A, et al. Circulating interleukin- 6 as a tumor marker for hepatocellular carcinoma. Ann Oncol 2008;19:353-358. doi: 10.1093/annonc/mdm448.

[8] Hibi M, Murakami M, Saito M, Hirano T, Taga T, Kishimoto T. Molecular cloning and expression of an IL-6 signal transducer, gp130. Cell 1990;63:11491157. doi: 10.1016/0092-8674(90)90411-7.

[9] Baatout S. Interleukin-6 and megakaryocytopoiesis: an update. Ann Hematol 1996;73:157-162. doi: 10.1007/s002770050220.

[10] Peters M, Jacobs S, Ehlers M, Vollmer P, Müllberg J, Wolf E, et al. The function of the soluble interleukin 6 (IL-6) receptor in vivo: sensitization of human soluble IL- 6 receptor transgenic mice towards IL- 6 and prolongation of the plasma half-life of IL-6. J Exp Med 1996;183:1399-1406. doi: 10.1084/jem. 183.4.1399.

[11] Matthews V, Schuster B, Schutze S, Bussmeyer I, Ludwig A, Hundhausen C, et al. Cellular cholesterol depletion triggers shedding of the human interleukin-6 receptor by ADAM10 and ADAM17 (TACE). J Biol Chem 2003;278: 38829-38839. doi: 10.1074/jbc.M210584200.

[12] Jones SA, Scheller J, Rose-John S. Therapeutic strategies for the clinical blockade of IL-6/gp130 signaling. J Clin Invest 2011;121:3375-3383. doi: $10.1172 /$ JCI57158.

[13] Jones SA, Richards PJ, Scheller J, Rose-John S. IL-6 transsignaling: the in vivo consequences. J Interferon Cytokine Res 2005;25:241-253. doi: 10.1089/jir. 2005.25.241.

[14] Hirano T, Yasukawa K, Harada H, Taga T, Watanabe $Y$, Matsuda T, et al. Complementary DNA for a novel human interleukin (BSF-2) that induces B lymphocytes to produce immunoglobulin. Nature 1986;324:73-76. doi: 10 . $1038 / 324073 \mathrm{a0}$.

[15] Kishimoto T. Interleukin-6: discovery of a pleiotropic cytokine. Arthritis Res Ther 2006;8:S2. doi: 10.1186/ar1916.

[16] Heinrich PC, Castell JV, Andus T. Interleukin- 6 and the acute phase response. Biochem J 1990;265:621-636. doi: 10.1042/bj2650621.

[17] Garcia-Zubiri C, Citores MJ, Yebra-Bango M. Contribution of monocytes to overproduction of interleukin-6 in a case of cardiac myxoma. Am J Med Sci 2009;338:336-337. doi: 10.1097/MAJ.0b013e3181ab8a62.

[18] Pahne-Zeppenfeld J, Schroer N, Walch-Ruckheim B, Oldak M, Gorter A, Hegde $S$, et al. Cervical cancer cell-derived interleukin-6 impairs CCR7dependent migration of MMP-9-expressing dendritic cells. Int J Cancer 2014;134:2061-2073. doi: 10.1002/ijc.28549.

[19] Cho HY, Lee SW. TLR5 activation by flagellin induces doxorubicin resistance via interleukin-6 (IL-6) expression in two multiple myeloma cells. Cell Immunol 2014;289:27-35. doi: 10.1016/j.cellimm.2014.03.003.
[20] Rohleder N, Aringer M, Boentert M. Role of interleukin- 6 in stress, sleep, and fatigue. Ann N Y Acad Sci 2012;1261:88-96. doi: 10.1111/j.1749-6632. 2012.06634.x.

[21] Kraakman MJ, Kammoun $\mathrm{HL}$, Allen TL, Deswaerte V, Henstridge DC, Estevez $\mathrm{E}$, et al. Blocking IL- 6 trans-signaling prevents high-fat diet-induced adipose tissue macrophage recruitment but does not improve insulin resistance. Cell Metab 2015;21:403-416. doi: 10.1016/j.cmet.2015.02.006.

[22] Hoge J, Yan I, Janner N, Schumacher V, Chalaris A, Steinmetz OM, et al. IL-6 controls the innate immune response against Listeria monocytogenes via classical IL-6 signaling. J Immunol 2013;190:703-711. doi: 10.4049/ jimmunol.1201044.

[23] van der Poll T, Keogh CV, Guirao X, Buurman WA, Kopf M, Lowry SF. Interleukin- 6 gene-deficient mice show impaired defense against pneumococcal pneumonia. J Infect Dis 1997;176:439-444. doi: 10.1086/514062.

[24] Puel A, Picard C, Lorrot M, Pons C, Chrabieh M, Lorenzo L, et al. Recurrent staphylococcal cellulitis and subcutaneous abscesses in a child with autoantibodies against IL-6. J Immunol 2008;180:647-654. doi: 10.4049/jimmunol. 180.1.647.

[25] Hunter CA, Jones SA. IL-6 as a keystone cytokine in health and disease. Nat Immunol 2015;16:448-457. doi: 10.1038/ni.3153.

[26] Semerano L, Thiolat A, Minichiello E, Clavel G, Bessis N, Boissier MC. Targeting IL-6 for the treatment of rheumatoid arthritis: Phase II investigational drugs. Expert Opin Investig Drugs 2014;23:979-999. doi: 10.1517/135437 84.2014.912276.

[27] Cekic C, Arabul M, Alper E, Pakoz ZB, Saritas E, Yuksel, et al. Evaluation of the relationship between serum ghrelin, $C$-reactive protein and interleukin- 6 levels, and disease activity in inflammatory bowel diseases. Hepatogastroenterology 2014;61:1196-1200.

[28] Otani N, Morishita Y, Oh I, Saito O, Takemoto F, Muto S, et al. Successful treatment of a mesangial proliferative glomerulonephritis with interstitial nephritis associated with Castleman's disease by an anti-interleukin- 6 receptor antibody (tocilizumab). Intern Med 2012;51:1375-1378. doi: 10.2169/ internalmedicine.51.6555.

[29] Suematsu S, Matsuda T, Aozasa K, Akira S, Nakano N, Ohno S, et al. IgG1 plasmacytosis in interleukin 6 transgenic mice. Proc Natl Acad Sci USA 1989; 86:7547-7551. doi: 10.1073/pnas.86.19.7547.

[30] Campbell IL, Abraham CR, Masliah E, Kemper P, Inglis JD, Oldstone MB, et al. Neurologic disease induced in transgenic mice by cerebral overexpression of interleukin 6. Proc Natl Acad Sci USA 1993;90:10061-10065. doi: 10.1073/ pnas.90.21.10061.

[31] DiCosmo BF, Geba GP, Picarella D, Elias JA, Rankin JA, Stripp BR, et al. Airway epithelial cell expression of interleukin- 6 in transgenic mice. Uncoupling of airway inflammation and bronchial hyperreactivity. J Clin Invest 1994;94: 2028-2035. doi: 10.1172/JCI117556.

[32] Brieva JA, Martin RA, Martinez-Maza O, Kagan J, Merrill J, Saxon A, et al. Interleukin 6 is essential for antibody secretion by human in vivo antigen-induced lymphoblastoid B cells. Cell Immunol 1990;130:303-310. doi: 10.1016/ 0008-8749(90)90273-T.

[33] Kishimoto T, Taga T, Yamasaki K, Matsuda T, Tang B, Muraguchi A, et al. Normal and abnormal regulation of human $B$ cell differentiation by a new cytokine, BSF2/IL-6. Adv Exp Med Biol 1989;254:135-143. doi: 10.1007/ 978-1-4757-5803-0_16.

[34] Dienz O, Eaton SM, Bond JP, Neveu W, Moquin D, Noubade R, et al. The induction of antibody production by IL- 6 is indirectly mediated by IL-21 produced by CD4+ T cells. J Exp Med 2009;206:69-78. doi: 10.1084/jem. 20081571.

[35] Harker JA, Lewis GM, Mack L, Zuniga EI. Late interleukin-6 escalates T follicular helper cell responses and controls a chronic viral infection. Science 2011;334:825-829. doi: 10.1126/science.1208421.

[36] Hou W, Jin YH, Kang HS, Kim BS. Interleukin-6 (IL-6) and IL-17 synergistically promote viral persistence by inhibiting cellular apoptosis and cytotoxic T cell function. J Virol 2014;88:8479-8489. doi: 10.1128/JVI.00724-14.

[37] Zhang F, Yao S, Zhang M, Yuan J, Chen X, Zhou B. Roles of circulating soluble interleukin (IL) -6 receptor and IL- 6 receptor expression on CD4+ T cells in patients with chronic hepatitis B. Int J Infect Dis 2011;15:e267-e271. doi: $10.1016 /$ j.ijid.2010.12.008.

[38] Tan AT, Koh S, Goh W, Zhe HY, Gehring AJ, Lim SG, et al. A longitudinal analysis of innate and adaptive immune profile during hepatic flares in chronic hepatitis B. J Hepatol 2010;52:330-339. doi: 10.1016/j.jhep. 2009.12.015.

[39] Heinz D, Peters M, Prange R, Gerken G, Rose-John S. Possible role of human interleukin- 6 and soluble interleukin- 6 receptor in hepatitis $B$ virus infection. J Viral Hepat 2001;8:186-193. doi: 10.1046/j.1365-2893.2001.00281.x.

[40] Yoffe B, Noonan CA, Melnick JL, Hollinger FB. Hepatitis B virus DNA in mononuclear cells and analysis of cell subsets for the presence of replicative intermediates of viral DNA. J Infect Dis 1986;153:471-477. doi: 10.1093/ infdis/153.3.471.

[41] Fan WH, Han QY, Hu YP, Zhang HL. Dynamic change and clinical significance of serum IL- 6 and IL-8 in patients with hepatitis B. Shanghai J Immunol 1997(05):293-294. 
[42] Wang JY, Liu P. Abnormal immunity and gene mutation in patients with severe hepatitis-B. World J Gastroenterol 2003;9:2009-2011. doi: 10.3748/ wjg.v9.i9.2009.

[43] Kakumu S, Shinagawa T, Ishikawa T, Yoshioka K, Wakita T, Ito Y, et al. Serum interleukin 6 levels in patients with chronic hepatitis B. Am J Gastroenterol 1991;86:1804-1808.

[44] Pan C], Wu HL, Kuo SF, Kao JH, Tseng TC, Liu CH, et al. Serum interleukin 6 level correlates with outcomes of acute exacerbation of chronic hepatitis B. Hepatol Int 2011;6:591-597. doi: 10.1007/s12072-011-9299-2.

[45] Zhang W, Yue B, Wang GQ, Lu SL. Serum and ascites levels of macrophage migration inhibitory factor, TNF- $\alpha$ and IL- 6 in patients with chronic virus hepatitis B and hepatitis cirrhosis. Hepatobiliary Pancreat Dis Int 2002;1: 577-580.

[46] De Meyer S, Gong ZJ, Suwandhi W, van Pelt J, Soumillion A, Yap SH. Organ and species specificity of hepatitis $B$ virus (HBV) infection: a review of literature with a special reference to preferential attachment of HBV to human hepatocytes. J Viral Hepat 1997;4:145-153. doi: 10.1046/j.1365-2893.1997. 00126.x.

[47] Hosel M, Quasdorff M, Wiegmann K, Webb D, Zedler U, Broxtermann M, et al. Not interferon, but interleukin-6 controls early gene expression in hepatitis $B$ virus infection. Hepatology 2009;50:1773-1782. doi: 10.1002/hep.23226.

[48] Ohno H, Kaneko S, Kobayashi K, Murakami S. Human hepatitis B virus enhancer 1 is responsive to human interleukin-6. J Med Virol 1997;52:413418. doi: 10.1002/(SICI)1096-9071(199708)52:4<413: :AID-JMV122-H.

[49] Chou CH, Chen PJ, Jeng YM, Cheng AL, Huang LR, Cheng JC. Synergistic effect of radiation and interleukin- 6 on hepatitis $B$ virus reactivation in liver through STAT3 signaling pathway. Int J Radiat Oncol Biol Phys 2009;75: 1545-1552. doi: 10.1016/j.ijrobp.2008.12.072.

[50] Lee Y, Park US, Choi I, Yoon SK, Park YM, Lee YI. Human interleukin 6 gene is activated by hepatitis $B$ virus-X protein in human hepatoma cells. Clin Cancer Res 1998;4:1711-1717.

[51] Waris G, Siddiqui A. Interaction between STAT-3 and HNF-3 leads to the activation of liver-specific hepatitis B virus enhancer 1 function. J Virol 2002;76:2721-2729. doi: 10.1128/JVI.76.6.2721-2729.2002.

[52] Xiang WQ, Feng WF, Ke W, Sun Z, Chen Z, Liu W. Hepatitis B virus X protein stimulates IL- 6 expression in hepatocytes via a MyD88-dependent pathway. J Hepatol 2011;54:26-33. doi: 10.1016/j.jhep.2010.08.006.

[53] Kuo TM, Hu CP, Chen YL, Hong MH, Jeng KS, Liang CC, et al. HBV replication is significantly reduced by IL-6. J Biomed Sci 2009;16:41. doi: 10.1186/14230127-16-41.

[54] Klein C, Wustefeld T, Assmus U, Roskams T, Rose-John S, Müller M, et al. The IL-6-gp130-STAT3 pathway in hepatocytes triggers liver protection in T cell-mediated liver injury. J Clin Invest 2005;115:860-869. doi: 10.1172/ JCI23640.

[55] Marra M, Sordelli IM, Lombardi A, Lamberti M, Tarantino L, Giudice A, et al. Molecular targets and oxidative stress biomarkers in hepatocellular carcinoma: an overview. J Transl Med 2011;9:171. doi: 10.1186/1479-5876-9171.

[56] Feitelson MA, Lee J. Hepatitis B virus integration, fragile sites, and hepatocarcinogenesis. Cancer Lett 2007;252:157-170. doi: 10.1016/j.canlet. 2006.11.010.
[57] Pan J, Lian Z, Wallett $S$, Feitelson MA. The hepatitis B $x$ antigen effector, URG7, blocks tumour necrosis factor alpha-mediated apoptosis by activation of phosphoinositol 3-kinase and beta-catenin. J Gen Virol 2007;88:32753285. doi: 10.1099/vir.0.83214-0.

[58] Yamashita T, Budhu A, Forgues M, Wang XW. Activation of hepatic stem cell marker EpCAM by Wnt-beta-catenin signaling in hepatocellular carcinoma. Cancer Res 2007;67:10831-10839. doi: 10.1158/0008-5472.CAN-07-0908.

[59] Li CH, Xu F, Chow S, Feng L, Yin D, Ng TB, et al. Hepatitis B virus X protein promotes hepatocellular carcinoma transformation through interleukin- 6 activation of microRNA-21 expression. Eur J Cancer 2014;50:2560-2569. doi: 10.1016/j.ejca.2014.07.008.

[60] Chang TS, Wu YC, Chi CC, Su WC, Chang PJ, Lee KF, et al. Activation of IL6/IGFIR confers poor prognosis of HBV-related hepatocellular carcinoma through induction of OCT4/NANOG expression. Clin Cancer Res 2015;21: 201-210. doi: 10.1158/1078-0432.CCR-13-3274.

[61] Yan $\mathrm{H}$, Zhong G, Xu G, He W, Jing Z, Gao Z, et al. Sodium taurocholate cotransporting polypeptide is a functional receptor for human hepatitis and D virus. ELife 2012;1:e00049. doi: 10.7554/eLife.00049.

[62] Bouezzedine F, Fardel O, Gripon P. Interleukin 6 inhibits HBV entry through NTCP down regulation. Virology 2015;481:34-42. doi: 10.1016/j.virol. 2015.02.026

[63] Park BL, Lee HS, Kim YJ, Kim JY, Jung JH, Kim LH, et al. Association between interleukin 6 promoter variants and chronic hepatitis B progression. Exp Mol Med 2003;35:76-82. doi: 10.1038/emm.2003.11.

[64] Cox ED, Hoffmann SC, DiMercurio BS, Wesley RA, Harlan DM, Kirk AD, et al. Cytokine polymorphic analyses indicate ethnic differences in the allelic distribution of interleukin-2 and interleukin-6. Transplantation 2001;72: 720-726.

[65] Ognjanovic S, Yuan JM, Chaptman AK, Fan Y, Yu MC. Genetic polymorphisms in the cytokine genes and risk of hepatocellular carcinoma in low-risk non-Asians of USA. Carcinogenesis 2009;30:758-762. doi: 10.1093/carcin/bgn286.

[66] Lu Y, Peng J, Wang C, Zhu Y, Wang F, Sun Z. IL-6 promoter functional polymorphism $-572 C / G$ affects spontaneous clearance of hepatitis $B$ virus infection. Clin Lab 2014;60:1903-1907.

[67] Dai Y, Liu XL, Chai OB, Gai YH, Li Y, Liu BG. Relationship between the-572G/C polymorphism in IL-6gene promoter and hepatitisvirus $B$ infection in ChineseHan population. Wor Chin J Dig 2009:1522-1526.

[68] Qiu XQ, Bei CH, Yu HP, Zeng XY, Zhong QA. Study on the relationship between single-nucleotide polymorphisms in IL-6, IL-10 genes and HBV-related hepatocellular carcinoma. Zhonghua Liu Xing Bing Xue Za Zhi 2011;32: 510-513.

[69] Saxena R, Chawla YK, Verma I, Kaur J. IL-6(-572/-597) polymorphism and expression in HBV disease chronicity in an Indian population. Am J Hum Biol 2014;26:549-555. doi: 10.1002/ajhb.22562.

[70] Yao X, Huang J, Zhong H, Shen N, Faggioni R, Fung M, et al. Targeting interleukin- 6 in inflammatory autoimmune diseases and cancers. Pharmacol Ther 2014;141:125-139. doi: 10.1016/j.pharmthera.2013.09.004.

[71] Angevin E, Tabernero J, Elez E, Cohen SJ, Bahleda R, van Laethem JL, et al. A phase I/II, multiple-dose, dose-escalation study of siltuximab, an anti-interleukin-6 monoclonal antibody, in patients with advanced solid tumors. Clin Cancer Res 2014;20:2192-2204. doi: 10.1158/1078-0432. CCR-13-2200. 